academic beds following three unrelated suicides; a major setback for Midlands' psychiatry.

I was fortunate in serving on the first College Council and its Executive and Finance Committee. These were heady days, full of interest and anxiety, for we were aware that if the College got off to a bad start the future of our specialty would be jeopardised. The lease at Chandos House was running out and we had to find a new home urgently. I recall a special meeting when a few of us had to decide whether or not to go ahead with the purchase of 17 Belgrave Square. I was convinced that we would all land in Queer Street but Wilfred Warren had handled our investments with consummate skill so we were able to make a down payment while Martin Roth got the necessary financial backing, thanks largely to Lord Goodman. Early Council meetings were given over to much free floating discussion interspersed by hilarious anecdotes from our President, who had many gifts but little sense of time. We were often still on 'matters arising' in the late afternoon, despite Trethowan's insistence that we only discussed 'starred items'. Things were to change dramatically when Linford Rees took over, when the agenda was efficiently dispatched well before lunch, but I found these meetings less therapeutic. Subsequent Presidents have each stamped College procedures with their personalities, a vindication of our democratic structure. Largely on the insistence of colleagues I spent the last decade of my career sitting on innumerable committees. I became overcommitted and felt I no longer did anything properly, but when I expressed my frustration I was told nobody had noticed any difference in my performance.

What have I learned during my psychiatric career? Not much really. To-day's conviction becomes tomorrow's fiction. We must be prepared to abandon our most cherished beliefs when evidence suggests they are myths but meanwhile we must continue to treat patients the best way we can. You have to stay in one place for a long time before you have much impact. A sense of humour is a vital defence for survival in psychiatry. My hope for the future? A better integration of the biological and psychological approaches to psychiatry.

\title{
Observations of mental health care programmes for schizophrenic patients in Toronto
}

\author{
MARION M. KeMP, Senior Registrar, Greater Glasgow Health Board, Glasgow
}

Toronto is a large multicultural society with a metropolitan population of several million people. It is mainly English-speaking, although it contains Portuguese, Chinese, Italian and other communities. Although similar in population to the larger industrial cities of the United Kingdom, and despite a common language, there are important cultural differences which are relevant when assessing treatment programmes. In particular, in contrast to the urban decay, high unemployment rates, and increasing number of elderly residents prevalent in UK cities, Toronto is a young, thriving city with a low unemployment rate and affluent population. There is a low crime rate, little evidence of vandalism, but ample evidence of an advanced structure, e.g. public transport, play schemes etc. Accommodation is, however, expensive and mainly in private ownership.

The Canadian Health Service is a liberal health care system with state and independently managed hospitals. This gives rise to fragmented implementation of policies but allows for innovative programme development. The business approach to health care is much in evidence. Good public relations are encouraged. Clients, i.e. patients, are provided with attractive settings for group and out-patient clinics, and public information films are available describing the content of particular approaches to patterns of care. Staff are considered to be valuable assets and the increased competition for their services results in a greater mobility of staff between hospitals. The working environment for staff is often arranged to promote maximum staff interaction with consequent advantages to the generation and discussion of ideas. The mode of practice of psychiatry has been greatly influenced by the American psychiatrists and in particular by psychosocial models of illness. The main approach to therapy is client-centred.

The financing of health care in Ontario is paid for by the working population under the Ontario Health Insurance Premium (OHIP). Those in receipt of welfare payments are also covered. There is no catchment area system for the independently operated hospitals. Patients may choose which particular hospital they attend, and thus to some extent the specialist who will look after them. The Canadian is a 
consumer or client rather than a patient and the paternalistic style of the British practitioner is inappropriate. Discussions regarding aspects of psychological illness are frequent in the newspapers and contributions from professionals are commonplace. The impression given is that the public are better informed with regard to psychological illnesses and treatment procedures. Practitioners appear to be under greater public pressure, which is to be expected in a consumer-orientated society.

The Primary Care Team, as we know it in Britain, is less well developed for various reasons. The nature of the population is such that people move more frequently and therefore are less likely to remain with the one general practitioner. In Toronto, there is easier access to specialists and the general practitioner is more likely to refer clients for specialist care. Because the general practitioner does not occupy the same important role in the management of patients, he is not as involved in detention procedures under the Mental Health Act.

The lack of an integrated primary health care team means that a variety of health care workers have evolved to cater for the needs of the mentally ill. Some of these have remits not paralleled in Britain, and those whose function is basically similar do not operate from the same base. Professionals include Community Occupational Therapy Association (COTA) workers; public health nurses, who are similar to district nurses but who operate from a public health clinic rather than a general practitioner's surgery or health centre; homecare workers, who act as short term liaison workers and who liaise with the other required services when patients are discharged from hospital; community nurses who at present are a relatively small group; social workers who again operate from a smaller less integrated network and case managers,' a unique group of workers, who have evolved as a direct result of the large number of chronically mentally ill persons in the community as a consequence of the programme of discharge of patients from hospital into the community. These case managers may be from a variety of different training backgrounds; however, the governmentsponsored case managers are required to have undergone training in rehabilitation.

Case managers have a workload of between 10 and 20 chronic patients who are now living in the community. Their role may be defined by various theoretical models based on a psychosocial model of treatment. They co-ordinate the delivery of services to the chronic psychiatric patient in the community thereby, it is hoped, to improve continuity of care. The 'client' is encouraged to identify aims and goals by exploring his/her current situation in general, and specific aspects of his/her life in particular, be it in daily living, work environment or in social skills. The goals are defined by seeking and evaluating the client's values, skills and weaknesses, defining the necessary resources required to achieve these goals, then facilitating contact with the appropriate services. Critics of the concept of case management see their development as a direct consequence of patients becoming lost in the maze of fragmented service provision.

Improving the management of schizophrenic patients in the community necessitated mobilising public opinion in favour of the psychiatric patient by a variety of methods. An aggressive public education programme operates, e.g. the patients from the Clarke Institute in Toronto have participated in a documentary which describes the feelings, hopes and despairs of patients and relatives whose lives had been affected by this distressing condition. Patients and relatives are provided with explanatory pamphlets describing the main symptoms of the disease, the reasons for medication and its likely side effects. Advice is given for coping with various problems on discharge from hospital. All programmes appeared as far as possible to create a supportive environment and an enthusiastic optimistic approach towards patients and their relatives, paving the way for good long-term management.

Services for schizophrenic patients at the Clarke Institute of the University of Toronto include a crisis unit, a day care programme committed to long-term support and in-patient wards. The ward which I visited has a clearly stated philosophy of care. There is considerable emphasis on patient education about their particular disease and about the need for close contact with the unit and the need for regular medication. Despite being informed about the side effects of medication, and the active discussion of such matters in medication groups, most patients agreed to have treatment. The patients in this particular setting are aware of their diagnosis. The intention is that schizophrenia should be destigmatised and regarded in the same way as any other chronic disease process, e.g. diabetes. Some patients have been taught how to inject themselves with their depot preparation. It is believed that, in general, a much too pessimistic outlook has been adopted towards the disease in the past and that a more optimistic attitude should be encouraged. $^{2}$ A recurring theme is the importance of continuity of care for this group of patients, and perhaps the lot of the psychotic patient is undergoing a decline because it was pointed out to me on several occasions that working especially with chronic mentally ill people is unpopular. Staff are aware of the possibility of suffering from 'burn-out. ${ }^{3}$ Contrary to typical Freudian beliefs, I was informed that schizophrenic patients form intense transference reactions and require extremely sensitive management. Those who work primarily with this group of patients take this into account when organising day patient programmes and arranging follow-up. Each patient has a co-therapist drawn from the multi- 
disciplinary team in an attempt to alleviate problems of dependency should one worker cease to be part of the treatment team. The psychiatrist always remains in overall charge of the case. Attention to those details is considered to be important in preventing relapse.

The day unit runs a very highly organised volunteer group. These people are all screened and given basic information about mental illness. They are used to provide much needed social interaction in a non-threatening way. Many are university students, some are ex-patients. They form a diverse group. The patients are free to attend any of the daily groups and have easy access to the psychiatrist. It is appreciated that the peculiarities of the schizophrenic patient's illness are such that adhering to rules regarding access to staff should be flexible. Volunteers are used to promote social interaction and increase or replace existing social networks. In addition, the exposure of volunteers to psychiatric patients helps educate the public about mental health needs.

Social network therapy ${ }^{4}$ is an attempt, as one clinician put it, to create a protective shell around the patient and to promote social skills and competence within a constructive dependency. The patient's lack of these naturally occurring networks could be attributed to loss through the inevitable tensions created in a family by the patient's illness, or failure to develop socialisation skills because illness had started in early adolescence.

The day patient groups which I observed for schizophrenic patients, although adhering to basic rules, are of a much more flexible nature and considerable emphasis is put on providing a warm accepting atmosphere. Tea, coffee and sandwiches are always provided and the patients are free to walk about if they wish. Always the patient is regarded as a client, with a degree of autonomy. Although primarily psychotherapeutic in approach, the aim of treatment is the same as that of behavioural methods; namely to establish a therapeutic alliance, to capitalise on assets and to minimise weaknesses.

Patients and staff, including the consultant, participate in social activities such as card games and volleyball. It is apparent that these patients are very much aware that they have failed in some way in their lives, that they have a low self esteem and that they desperately want to succeed at something even if it is just winning at cards (but not being deliberately allowed to win). The interactions during games allow a much more realistic assessment of attention and concentration than one might get at an ordinary outpatient clinic and it was interesting to see a seemingly apathetic, withdrawn patient become animated during volleyball.

One of the most innovative groups which I attended was for schizophrenic parents and their children. The staff have monitored these people and their families for some years. The group is intended to foster parenting skills and provide support. As a clinician, I found it an ideal way to observe family interaction and communication patterns.

All the groups provided a fascinating view of how the schizophrenic patient feels about his illness, about his fears, hopes and disappointments, and about his anger because of loss of the normal expectations from life.

From the main university programmes I then went on to visit the state-run hospital on Queen Street, in downtown Toronto. It is interesting to note that although the original street number of the building was the same as the telephone number for emergency services, the building number was changed as part of a drive to destigmatise it. It is now called Queen Street Mental Health Centre. It is a 614-bedded facility and operates eight satellite community clinics. The building, originally a typical old asylum, has been replaced by a modern building. The staff, however, are quick to point out their disappointment at the new building being built along typical mental hospital lines, with long corridors and large areas of bare cement wash. However, despite these disappointments, the staff appeared very enthusiastic.

It is interesting to note that the model of rehabilitation adopted also takes into account issues of dependency and uses the concept of co-therapy while still carrying out what was essentially a behaviourally oriented programme.

It seems that the state hospital system is catering for the more disturbed and more chronic type of patient and those who have failed in earlier more optimistic programmes.

As indicated earlier, there are eight satellite clinics spread around the city. The first to be set up, which serves the Parkdale area, is known as Archways. This is a poor, dilapidated area of the city similar to our own inner cities but perhaps no worse. Despite the efforts to integrate the clinic into the community, one could not help feeling that to some extent it still exists as an institution in the community rather than as ex-patients being harmoniously absorbed and integrated. Patients wait in cafés for the community clinic to open. Some ask passers-by for money. This was an invaluable chance to observe a community care programme which had already passed through the stages from conception to implementation to public alarm; stages yet to be negotiated in Scotland, which, in this respect, is further behind than England.

Archways has a Community Board of Directors and is operated by the Queen Street Mental Health Centre. It has two programmes, clinical services and case management services. The clinical services are provided by a multi-disciplinary team of professionals from nursing, psychiatry, psychology, social work, occupational therapy, recreation and vocational rehabilitation. The clinic has been set up to provide: 
(a) preventive services, e.g. educational workshops and community liaison activities in order to develop a community network of mental health services

(b) community mental health direct services such as crisis intervention, client counselling, individual and group therapy and case management

(c) consulting and research services to the community in defining mental health needs and developing appropriate programmes.

It operates mainly during office hours and some evenings.

The history of Archways is interesting and provides insights into Community Health Care. Its development started in 1974 as a result of concerns expressed by community workers and their staff about the plight of patients in the local community of Parkdale, which had received a large number of psychiatric patients following an active discharge of patients from hospital. A community board with interested persons from the community was set up in 1976. The rent for the original premises was paid for by donations. The main function was as a resource centre offering clinics, counselling and crisis intervention as well as help with social needs. Seven full-time staff were employed.

By 1980 , from these modest beginnings, there were four satellite clinics whose financial needs were acknowledged by the government. The Parkdale Residents' Association and the Parkdale Businessmen's Association were active in campaigning to have something done for the ex-patients. By 1982, a case management programme was suggested, and by 1983 this was provided by central government. In 1984, a co-ordinator of case managers and 10 case managers were hired. It is designed to serve 200 clients. Two additional staff are consultant psychiatrists on contract. There are two psychiatric residents, a full-time recreationist, a part-time assistant, and three clerical support staff. A total of 31 permanent positions are complemented by nursing students, chaplaincy internees and art therapy trainees.

The community liaison service is a vital aspect of the clinic's work and is provided to the $\mathbf{4 0}$ other agencies who provide services to local residents. It works in close collaboration with the Community Advisory Board which assists with fund-raising and community concerns. The liaison work could even involve teaching restaurant staff how to cope with oddities of behaviour. Despite these good intentions, it is significant to note that an active advocate for the ex-psychiatric patients indicated that due to pressure from colleagues he had to withdraw from these activities.

In respect of ex-patient residences, the sample demonstrated by case managers, whether representative of community care facilities as a whole or not, indicates an area of concern for those involved in community care. It was apparent that the best quality of patient lives in the best facilities but even there the owners are keen to have the patients engaged in a programme and out of the residence as much as possible. The facility with the most attractive residencies was regimented. Owners dislike young unstable psychotic patients as residents. Some prefer withdrawn apathetic patients who, although not tending to involve themselves in outside activities, will sit unobtrusively in the residence. Carpets in some homes are dirty and rooms are dingy. One owner had arranged old metal hospital beds in a row in an uncarpeted room which, despite various regulations, had no personal storage facilities. Another house had the sitting area in a dark, dingy basement.

It is obvious from these brief observations that to embark on an aggressive programme towards community care necessitates adequate supervisional machinery, adequate support services, public, staff, and patient education programmes. It is interesting that the same complaints of exploitation and abuse of patients' rights previously expressed when discussing defects in institutional care were also applicable to community care.

By the setting up of Archways and its sister clinics, it is evident that the Canadian government has accepted that a problem exists in relation to its community care programme. In many ways, Canadians have a more enlightened and informed attitude to mental illness. There are excellent, innovative treatment programmes. Despite this their community care programme has had difficulties. We may be able to learn from their experiences.

\section{Acknowledgement}

I would like to thank Drs John Thornton and Joel Jeffries of the Clarke Institute and the staff of Queen Street Mental Health Centre and of the Archways Clinic for their help.

\section{References}

${ }^{1}$ INTAGLIA, J. (1982) Improving the quality of community care for the chronically mentally disabled: The role of case management. Schizophrenia Bulletin, 8, 655-674.

${ }^{2}$ THORNTON, J. F. \& SHUGER, G. (1985) The schizophrenic and his family: A guide for the family practitioner. Modern Medicine of Canada, 40, 785-790.

${ }^{3}$ LAMB, H. R. (1979) Staff burnout in work with long term patients. Hospital and Community Psychiatry, 30, 396-398.

${ }^{4}$ Morin, R. C. \& Seidman, E. (1986) A social network approach and the revolving door patient. Schizophrenia Bulletin, 12, 262-273. 